Article

\title{
An Evidence of Distributed Trust in Blockchain-Based Sustainable Food Supply Chain
}

\author{
Jaehun Joo ${ }^{1, *(1)}$ and Yuming Han ${ }^{2}$ \\ 1 Department of Information Management, College of Management and Economics, \\ Dongguk University-Gyeongju, Gyeongju-si 780-714, Gyeongsangbuk-do, Korea \\ 2 Cooperative Program of International Business, Dongguk University, \\ Gyeongju-si 780-714, Gyeongsangbuk-do, Korea; 875816309hanyuming@gmail.com \\ * Correspondence: givej@dongguk.ac.kr; Tel.: +82-54-770-2346
}

check for updates

Citation: Joo, J.; Han, Y. An Evidence of Distributed Trust in

Blockchain-Based Sustainable Food Supply Chain. Sustainability 2021, 13, 10980. https://doi.org/10.3390/ su131910980

Academic Editors: Donghyun Choi, Bomi Song and Jinsung Rha

Received: 23 August 2021

Accepted: 30 September 2021

Published: 3 October 2021

Publisher's Note: MDPI stays neutral with regard to jurisdictional claims in published maps and institutional affiliations.

Copyright: (c) 2021 by the authors. Licensee MDPI, Basel, Switzerland. This article is an open access article distributed under the terms and conditions of the Creative Commons Attribution (CC BY) license (https:// creativecommons.org/licenses/by/ $4.0 /)$.

\begin{abstract}
It is necessary to identify what factors affect distributed trust and validate their effect on distributed trust and user satisfaction in an area of the food supply chain for sustainable business. The purpose of the present study is to examine determinants of distributed trust in the blockchain-based food supply chain and test seven hypotheses derived from the structural equation model integrating distributed trust, its three determinants, and user satisfaction. Transparency, traceability, and security are suggested as three determinants of distributed trust along the blockchain-based food supply chain. Data were collected from users of Chinese firms employing blockchain-based food supply chains to validate the research model and test the seven hypotheses. The present study contributes to clarifying the significance of distributed trust and suggesting evidence of its role in the food supply chain. The present study discussed trust-free systems based on blockchain technology related to sustainability through the findings.
\end{abstract}

Keywords: distributed trust; trust; blockchain; supply chain; smart contract; chaincode; transparency; traceability; sustainability

\section{Introduction}

Applications of blockchain technology to the supply chain enhance trust among stakeholders and increase the sustainability of businesses [1]. Stakeholders of the supply chain include growers, processors, carriers, distributors, retailers, customers, and regulators. They do not know each other well. Centralized systems integrating supply chains with RFID (Radio Frequency Identification) still have limitations in their transparency and information asymmetry among stakeholders [2-4]. Private or permissioned blockchain like Hyperledger Fabric [5] is more suitable to the supply chain compared to the public blockchain like Ethereum. Permissioned blockchain provides better alternatives to protect privacy among stakeholders and does not need a resource-intensive and expensive PoW (Proof of Work) consensus algorithm, contrary to Bitcoin and Ethereum.

Food safety is a crucial social issue [6]. In general, food safety problems in the supply chain result from the three factors of contamination, spoilage, and compromise. Contamination includes toxins, insects, bacteria, and viruses. Spoilage is associated with temperature, humidity, and expiration. Compromise refers to tampering, misrepresentation, and substitution. Failures in food safety management lead to distrust among stakeholders of the food supply chain, as well as consumers [7]. Permissioned blockchain has been mainly applied to the food supply chain since 2018. What kind of characteristics of the blockchain-based food supply chain bring distributed trust and user satisfaction? There have been many studies on distributed trust dealing with trust among nodes or entities of a distributed network by ensuring and enhancing security in distributed computing systems [8,9] and on distributed trust in the platform and sharing economy applying blockchain [10-12]. 
However, there were no empirical studies providing evidence on relationships among characteristics of permissioned blockchains, trust in supply chains, and user satisfaction.

The purpose of the present study is to examine determinants of distributed trust in the blockchain-based food supply chain and test seven hypotheses derived from the structural equation model integrating distributed trust, its three determinants, and users' satisfaction. Transparency, traceability, and security are suggested as three determinants of distributed trust in the blockchain-based food supply chain. Data were collected from users of Chinese firms employing blockchain-based food supply chains to validate the research model and test the seven hypotheses. The present study contributes to clarifying the significance of distributed trust and suggesting the evidence of its role in a sustainable food supply chain.

\section{Blockchain-Based Food Supply Chain}

\subsection{Three Characteristics of Blockchain-Based Food Supply Chain}

Blockchain is one of the most promising technologies for innovating business ecosystems in the supply chain. Blockchain enables secure, reliable, and efficient distributed management systems without a trusted third party, which is a core part of centralized supply chain management [13]. There are vital components of blockchain technology that enable secure, transparent, traceable, and sustainable supply chain management as follows [13].

- $\quad$ Distributed peer-to-peer (P2P) network: Unstructured P2P network using flooding algorithm and TCP (Transmission Control Protocol)/IP (Internet Protocol).

- Public key cryptography (PKI) and hash algorithm: Elliptic curve cryptography (ECC), SHA (Secure Hash Algorithm)-256 and SHA-3, and Merkle tree or Merkle Patricia Tree for verifying data integrity.

- Consensus algorithm: A method of consensus decision-making among participants which are nodes of the blockchain network, where a new block, which is a set of valid transactions for a given time, is added to the existing blockchain. There are various consensus algorithms such as PoW, proof of stake (PoS), delegated proof of stake (DPoS), Byzantine fault tolerance (BFT), and crash fault Tolerant (CFT) [14].

- Smart contract: a self-executing contract with the agreement of stakeholders in the case of satisfying common contractual conditions written in computer codes containing a set of rules. The smart contract, which is called a chaincode in Hyperledger Fabric, plays an important role in ensuring distributed trust.

- Distributed ledger: Storage of transaction records that is consensually shared, replicated, and synchronized among participants in a distributed network. The distributed ledger includes blockchain and smart contracts in Hyperledger Fabric.

There are various blockchain platforms for supporting blockchain-based applications such as OpenChain, Corda, Etherium, and Hyperledger. Hyperledger Fabric is a promising platform for building supply chain management systems. Hyperledger Fabric is an opensource and distributed ledger platform initiated by Linux Foundation and a private or permissioned consortium blockchain network. IBM Food Trust is a typical example of blockchain-based supply chain applications in food safety management [7]. Walmart using IBM Hyperledger Fabric-based blockchain has been applying the blockchain to food safety since the implementation of projects in Chain and the US [7].

A participant or a stakeholder of a supply chain is called a client in Hyperledger Fabric and writes an application or a smart contract (called a chaincode in Hyperledger Fabric) of a transaction. Participants (called endorsing peers in Hyperledger Fabric) execute and validate the application and the smart contract. They (called ordering peers in Hyperledger Fabric) reach consensus through voting via consensus algorithm (BFT or CFT in Hyperledger Fabric). The validated and committed transactions are added to a new block and the related ledger is updated. Any transactions added to a block can never be modified or altered because all blocks are linked by using a hash algorithm which is SHA-256 or SHA-3. 
According to [2], considerable advancement in supply chain management has taken place since the 1990s, which has resulted in integrating the supply chain into enterprise resource planning (ERP). However, transparency and traceability are still a big challenge, in particular, with complex transactions. Transparency and traceability are the critical factors required in improving the quality of fresh foods [15]. A blockchain-based supply chain enhances transparency, traceability, and security, compared to conventional supply chain systems. The three characteristics described in Table 1 contribute to building distributed trust among stakeholders of the supply chain. The blockchain-based supply chain is more transparent than conventional systems in terms of openness, accessibility, and visibility. Blockchain provides higher visibility and accessibility in terms of information, inventory, and financial flows. The shared visibility of transactions, their validation, and distributed governance enable a high level of transparency. Stakeholders can track back, referring to where the food came from, and trace forward to determine who it was sold to, as needing the case of provenance and recall. Real-time sensor data across the supply chain are available to each stakeholder through a connection with IoT devices $[4,16]$. The system based on blockchain brings a higher level of transparency and traceability to all the stakeholders of the food supply chain including regulators and auditors. Distributed trust is not trust from the trusted third parties of conventional centralized systems but among stakeholders who are unknown to each other. Sustainability assuring the 3Ps (people, planet, and profit) and ESG (environment, society, and governance) is available from the blockchain-based supply chain because all stakeholders share information about human rights, the environment, and governance. They can also verify all related documents across the supply chain.

Table 1. Characteristics of the blockchain-based supply chain.

\begin{tabular}{|c|c|c|}
\hline Characteristics & Overview of Enabling Technology & Source \\
\hline $\begin{array}{l}\text { Transparency and } \\
\text { Traceability }\end{array}$ & $\begin{array}{l}\text { - All transactions, which were agreed upon by stakeholders through a consensus } \\
\text { algorithm, are shared in a secure and immutable distributed ledger. Smart } \\
\text { contracts make transactions traceable, transparent, and irreversible. } \\
\text { All stakeholders can confirm and trace those who are responsible for products at } \\
\text { any given time because smart contracts record ownership rights depending on } \\
\text { their changes in the supply chain and are stored in the blockchain network. } \\
\text { In particular, a channel component of Hyperledger Fabric that the stakeholders of } \\
\text { a supply chain can use to communicate with each other shows a validated ledger } \\
\text { to the relevant stakeholders of a blockchain. The channel enables eligible } \\
\text { stakeholders of a blockchain network to carry out transactions privately with each } \\
\text { other with a subset of other stakeholders. } \\
\text { Blockchain-based supply chain systems with IoT (Internet of Things) devices } \\
\text { improve the tracing ability and visibility. }\end{array}$ & {$[4,16-18]$} \\
\hline Security & $\begin{array}{l}\text { - PKI and cryptography provide confidentiality and privacy, data integrity, and } \\
\text { non-repudiation services in a blockchain. } \\
\text { - The Membership Service Provider (MSP) component of Hyperledger Fabric, } \\
\text { which assumes the roles of Certification Authority (CA) based on PKI provides } \\
\text { authenticity service in a blockchain network for protecting privacy. The channel of } \\
\text { Hyperledger Fabric plays a role in protecting privacy among stakeholders. }\end{array}$ & {$[17,18]$} \\
\hline
\end{tabular}

\subsection{A Survey of Blockchain-Based Food Supply Chain in China}

China has been facing a big problem of fake and counterfeited food, and most Chinese feel great anxiety about food safety. Chinese firms implemented applications of blockchain to the food supply chain for solving the problems of food safety. JD.com had collaborated with IBM to apply blockchain to logistics areas since 2016. JD released open-source blockchain systems called JD Chain in 2018. Over 1000 brands including farmers, processors, importers, and shippers participated in the blockchain systems. Consumers scan QR (Quick Response) codes or use NFC (Near Field Communication) with their mobile phones to track all the details of products at all stages throughout the supply chain and check their authenticity. 
In 2016, Walmart launched two blockchain projects by partnering with IBM. One is pork import from China. The other is mango import from America [7]. IBM developed a Food Trust system based on Hyperledger Fabric for improving food supply chain management. Walmart China collaborated with VeChain which is a platform offering a blockchain as a service to firms to enhance food tracking, traceability, and safety through the supply chain in 2019.

In 2018, a consortium known as the Food Trust Framework, which is a system for tracing food based on blockchain, was established for tracking food produced in China and applied to imports from Australia and New Zealand (products such as fish oil from Australia and dairy from New Zealand) in 2018. Merchants of Taobao and Tmall can use blockchain systems to verify the authenticity of products. Consumers can scan the QR codes of products with their mobile phones and get information about the place of origin and transaction history. Regulators can also monitor the supply chain. The purpose of the Food Trust system is to provide traceability and transparency in the food supply chain to stakeholders including growers, processors, distributors, regulators, and consumers. Recently, Alibaba globally provided blockchain solutions of supply chain management known as Alibaba Cloud BaaS (Blockchain as a Service). The BaaS combines cloud computing services, IoT, and blockchain solutions, which enables firms to build their own applications to guarantee traceability and transparency of supply chain systems [19].

\section{Research Model and Research Hypothesis}

Distributed trust refers to the belief in the blockchain-based system, which enables stakeholders who do not know each other well to trust through consensus among them without a third party [10]. First, blockchain-based systems allow participants to securely share transaction information among them without a third party. Second, it is really impossible to modify the transactions agreed upon by participants in the blockchain-based system. Finally, trust among participants comes not from individual trustworthiness, but the distributed system itself enabled by blockchain technology and smart contracts.

According to the authors of [10], the three stages of trust consist of local trust, institutional trust, and distributed trust. Local trust is related to trust based on one-to-one interactions and personal reputation among well-known people [10]. Institutional trust comes from institutional mechanisms ranging from reputations and brand images of the third party to things like insurance and contracts [10]. Distributed trust flows through networks, marketplaces, and platforms not from a single source like a third party, but across a variety of sources sharing responsibility by using blockchain technology and smart contracts [20] (p. 1) asserted that "the inherited characteristics of the blockchain enhance trust through transparency and traceability within any transaction of data, goods, and financial resources". Blockchain provides the ability to enhance transparency and traceability in transactions to organizations and, in turn, the increased transparency and traceability positively affect trust in organizations positively [21,22]. Blockchain allowing transactions and relevant data to be securely stored and verified without any trusted third parties enhances trust among participants. The characteristics of blockchain include transparency, traceability, and security [18].

In the presented study, distributed trust is defined as the degree to which supply chain stakeholders who do not know each other well trust counterparts and transactions in the blockchain-based food supply chain. Transparency is defined as the degree to which stakeholders of a food supply chain believe that transactions and related information are transparent. Traceability is the degree to which stakeholders of a food supply chain believe that they can track and trace all information about a product's origin, location, and history of a specified item across the food supply chain to verify when and where the item was produced by whom. Security is defined as the degree to which stakeholders of a supply chain perceive security services such as authentication, confidentiality, integrity, and non-repudiation from blockchain-based food supply chain. The three dimensions of blockchain such as transparency, traceability, and security are determinants of distributed 
trust and user's satisfaction of food supply chain systems as presented in a research model of Figure 1.

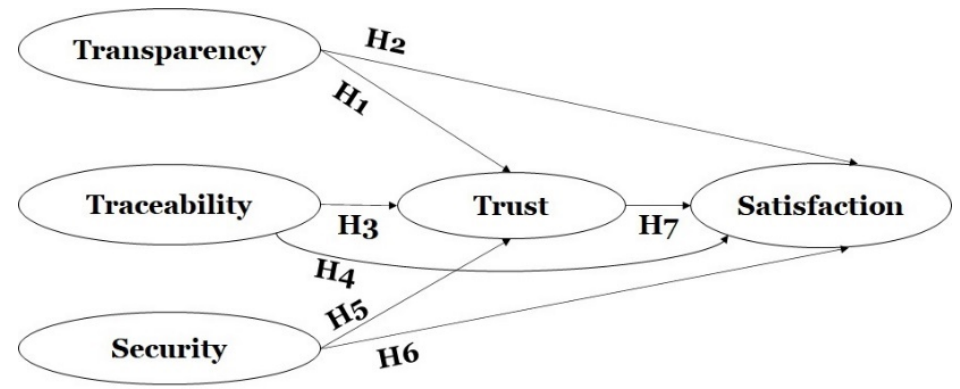

Figure 1. Research model.

In general, satisfaction includes a set of negative and affirmative responses in relation to the use of a system or technology and a type of emotional attitude [23]. Users' satisfaction is related to the extent to which their needs are satisfied by using a system or technology [23]. Ref. [24] defined customer satisfaction as the customer's perception of the degree to which the customer's requirements have been fulfilled. In the present study, satisfaction is defined as the degree to which stakeholders are satisfied with the blockchain-based food supply chain through their experience of its use as shown in Table 2.

Table 2. Operational definition of the concept.

\begin{tabular}{|c|c|c|}
\hline Concept & Definition & Source \\
\hline Transparency & $\begin{array}{l}\text { The degree to which stakeholders of a food supply chain believe that transactions and } \\
\text { related information are transparent. }\end{array}$ & {$[25,26]$} \\
\hline Traceability & $\begin{array}{l}\text { The degree to which stakeholders of a food supply chain believe that they can track and } \\
\text { trace all information about the origin, location, and history of a specified item along the } \\
\text { food supply chain to verify when and where the item was produced by whom. }\end{array}$ & {$[10,15,27,28]$} \\
\hline Security & $\begin{array}{l}\text { The degree to which stakeholders of the supply chain perceive security services such as } \\
\text { authenticity, confidentiality, integrity, and non-repudiation from the blockchain-based } \\
\text { food supply chain. }\end{array}$ & \\
\hline Distributed Trust & $\begin{array}{l}\text { The degree to which supply chain stakeholders who do not know each other well trust } \\
\text { their counterparts and transactions in the blockchain-based supply chain. }\end{array}$ & [10] \\
\hline Satisfaction & $\begin{array}{l}\text { The degree to which stakeholders of the supply chain satisfy the blockchain-based food } \\
\text { supply chain through their experience of their use. }\end{array}$ & {$[29,30]$} \\
\hline
\end{tabular}

Transparency refers to the ability to know what is happening upstream in the supply chain and to communicate this information among stakeholders across the supply chain [31]. A higher level of transparency is associated with consumer's willingness to pay $2 \%$ to $10 \%$ more for products through a transparent supply chain [31]. Transparency is directly associated with the provision of information to reduce uncertainty related to products or services [26]. Transparent information contributes to reducing uncertainty in supply chain systems. According to [26], there exists a significant positive relationship between transparency and trust. Blockchain transparency has a positive significant effect on supply chain performance [25]. Blockchain improves accessibility, visibility, accountability, and cooperation for stakeholders in the food supply chain [32]. Accordingly, transparency is an important determinant of trust and satisfaction. The present study posits the following hypotheses:

Hypothesis 1 (H1). Transparency has a positive influence on distributed trust in the blockchainbased food supply chain. 
Hypothesis 2 (H2). Transparency has a positive influence on satisfaction in the blockchain-based food supply chain.

Traceability refers to the ability to trace the origin, history, and location of an entity under consideration [24]. Ref [33] defined traceability as the process by which firms track materials and products and the conditions in which they were produced through the supply chain. Blockchain lets stakeholders of the supply chain track the status in real time and monitor the quality of products or services in real time. For example, a refrigerated container equipped with IoT devices can record any unsafe fluctuations on the blockchain [2]. Ref. [28] defined blockchain traceability as the ability to track and trace products and transaction documents including bill of lading and shipping notifications along the supply chain. Stakeholders of the supply chain can track and validate the origin of food by using a digital code with a digital signature [28]. An effective food traceability system is an important tool not only to manage food quality and safety risks but also to promote the development of effective food supply chain management [34]. Many food scandals and incidents have occurred in China. Traceability contributes to achieving consumer confidence in the food industry and helps to build customers' trust [27]. The present study posits the following hypotheses:

Hypothesis 3 (H3). Traceability has a positive influence on distributed trust in the blockchainbased food supply chain.

Hypothesis 4 (H4). Traceability has a positive influence on satisfaction in the blockchain-based food supply chain.

Many studies show evidence of a significant relationship between perceived security and consumers' trust in e-commerce [35]. According to [23], the security of banking systems has a significant positive effect on customer satisfaction. Ref. [36] argued that blockchain security contributes to improving trust among trade partners through in-depth interviews with industry experts. According to a study [2] on transparent and secure supply chains, one of the core functions of a blockchain is to enable an unlimited number of anonymous parties to transact securely with one another without a central third party. Accordingly, a transparent and secure supply chain increases stakeholders' trust in the food supply chain. Blockchain with channel function like Hyperledger Fabric assures privacy protection by prohibiting unauthorized participants' access to some secret information in the food supply chain. The present study posits the following hypotheses:

Hypothesis 5 (H5). Security has a positive influence on distributed trust in the blockchain-based food supply chain.

Hypothesis 6 (H6). Security has a positive influence on satisfaction in the blockchain-based food supply chain.

There have been many studies regarding the relationship between trust and satisfaction [37]. A study [37] regarding corporate social responsibility of telecommunication companies argued that customer satisfaction had a significant positive effect on customer trust. Ref. [38] showed a significant positive relationship between satisfaction and trust in the Airbnb context. Ref. [39] investigated the effect of trust on life satisfaction in the context of WeChat use in China. Trust in both individuals and institutions has a significant positive effect on life satisfaction [39].

Hypothesis 7 (H7). Distributed trust has a positive influence on satisfaction in the blockchainbased food supply chain. 


\section{Methodology: Measurement and Sampling Design}

Table 3 shows the measurement items for the five constructs in the proposed research model. A total of 28 question items were developed by referring to previous studies $[25,26]$. Each question item was measured on a five-point Likert scale. The survey was conducted with companies using the blockchain-based food supply chain. One sample from each company was collected. To reach users who are responsible for using a blockchain-based food supply chain in their firms, the present study employed purposive sampling and snowball sampling methods. Purposive sampling is a non-probability sampling method in which researchers rely on their own judgment when choosing samples. Snowball sampling is also a non-probability sampling method in which researchers recruit participants from among their acquaintances, and then, in turn, the informants introduce new participants to researchers. The questionnaire was published by using Wenjuanxing (www.wjx.ch (accessed on 5 November 2020)) which is the most popular website for online surveys in China and was sent out through WeChat or email for online survey. Each questionnaire was sent to supply chain representatives who were members of the China Animal Health and Food Safety Alliance (CAFA), which is a government-backed organization under the Chinese National Agricultural Science Technology Innovation Alliance. VeChain is one of the council members of CAFA. Excluding missing data, error responses, and inadequate answers, a total of 318 valid responses were used for the analyses.

Table 3. Measurement items.

\begin{tabular}{|c|c|c|}
\hline Concept & Measurement Item & Source \\
\hline Transparency & $\begin{array}{l}\text { TRANS1: I believe that all processes along blockchain-based supply chain are transparent. } \\
\text { TRANS2: I believe that stakeholders of food supply chain enable me to have a better } \\
\text { understanding of how blockchain based supply chain applications work. } \\
\text { TRANS3: I believe that stakeholders of food supply chain provide me with in-depth knowledge } \\
\text { about blockchain applications of the supply chain. } \\
\text { TRANS4: I believe that I have opportunities to provide feedback on blockchain-based food } \\
\text { supply chain. } \\
\text { TRANS5: I believe that I have transparent information about food transactions in the } \\
\text { blockchain-based supply chain. } \\
\text { TRANS6: I believe that I have complete information about food transactions in the } \\
\text { blockchain-based supply chain. }\end{array}$ & {$[25,26]$} \\
\hline Traceability & $\begin{array}{l}\text { TRACE1: I believe I can conveniently track all items of downstream processes along } \\
\text { blockchain-based food supply chain. } 85 \\
\text { TRACE2: I believe that it is easy to trace the location of all items along blockchain-based food } \\
\text { supply chain. } \\
\text { TRACE3: I believe that it is easy to trace the history of all items along blockchain-based food } \\
\text { supply chain } \\
\text { TRACE4: I believe that it is easy to verify all information ranging from the origin of a specified } \\
\text { item to its sale along blockchain-based food supply chain. } \\
\text { TRACE5: I believe that stakeholders of food supply chain enable me to have a better } \\
\text { understanding of how all items of transactions in the blockchain-based food supply chain can be } \\
\text { traced whenever I need to verify them. } \\
\text { TRACE6: I believe that stakeholders of food supply chain help me have a better understanding of } \\
\text { how all items of transactions in the blockchain-based food supply chain can be traced whenever I } \\
\text { need to verify them. }\end{array}$ & [28] \\
\hline Security & $\begin{array}{l}\text { SECUR1: I believe the blockchain-based food supply chain is safe from threats of hacking. } \\
\text { SECUR2: I believe the blockchain-based food supply chain is safe from risks of } \\
\text { information leakage. } \\
\text { SECUR3: I believe the blockchain-based food supply chain is safe from possibility of } \\
\text { information abuse. } \\
\text { SECUR4: I believe the blockchain-based food supply chain is safe from risks of data fabrication } \\
\text { and tampering. } \\
\text { SECUR5: I believe the blockchain-based food supply chain protects privacy well. }\end{array}$ & [40] \\
\hline
\end{tabular}


Table 3. Cont.

\begin{tabular}{ll}
\hline Concept & \multicolumn{1}{c}{ Measurement Item } \\
\hline & TRUST1: I believe all information of the blockchain-based food supply chain. \\
& TRUST2: I believe information integrity of the blockchain-based food supply chain. \\
& TRUST3: I believe that the blockchain-based supply chain service ensures food safety. \\
TRUST4: I believe stakeholders of the blockchain-based food supply chain keep my best interests \\
Distributed & in mind. \\
Trust & TRUST5: I expect stakeholders of the blockchain-based food supply chain to be sincere \\
& and genuine. \\
& TRUST6: Stakeholders of the blockchain-based food supply chain give the impression that they \\
& keep promises and commitments. \\
& TRUST7: Blockchain-based food supply chain services are trustworthy. \\
\hline & SATIS1: I am very satisfied with various functions of the blockchain-based food supply chain. \\
& SATIS2: I am very satisfied with information provided by the blockchain-based food \\
& supply chain. \\
SATIS3: I am very satisfied with all services of the blockchain-based food supply chain. \\
SATIS4: Compared to the previous supply chain, I am very satisfied with my use of the \\
incumbent blockchain-based food supply chain. \\
SATIS5: Compared to the previous supply chain, my satisfaction with the benefits provided by \\
the incumbent blockchain-based supply chain has improved.
\end{tabular}

\section{Analysis}

SPSS Statistics and SmartPLS [42] were used to analyze the survey data. Table 4 shows the demographic characteristics of respondents. Almost 50\% of the 318 respondents were male, and $68 \%$ of respondents had used their blockchain-based food supply chain systems for more than one year. Nearly $56 \%$ of the respondents were working for food processors and e-commerce companies.

Table 4. Respondents Demographics.

\begin{tabular}{|c|c|c|c|}
\hline Variable & Categories & Frequency & Percent \\
\hline \multirow{2}{*}{ Gender } & Male & 158 & 49.7 \\
\hline & Female & 160 & 50.3 \\
\hline \multirow{6}{*}{ Age } & Under 20 & 0 & 0.0 \\
\hline & $20-29$ & 85 & 26.7 \\
\hline & $30-39$ & 65 & 20.4 \\
\hline & $40-49$ & 66 & 20.8 \\
\hline & $50-59$ & 58 & 18.2 \\
\hline & Over 60 & 44 & 13.8 \\
\hline \multirow{3}{*}{ Experience } & Under 1 year & 101 & 31.8 \\
\hline & $1-2$ years & 129 & 40.6 \\
\hline & Over 2 years & 88 & 27.7 \\
\hline \multirow{5}{*}{ Type of firm } & Producer & 51 & 16.0 \\
\hline & Food Processor & 105 & 33.0 \\
\hline & e-Commerce & 74 & 23.3 \\
\hline & Distribution & 61 & 19.2 \\
\hline & Retail & 27 & 8.5 \\
\hline
\end{tabular}

Table 5 shows the path loadings connecting each construct to the indicator variables, VIF (Variance Inflation Factor), Cronbach's alpha, CR (Composite Reliability), and AVE (Average Variance Extracted). VIF is used to check for the problem of multicollinearity. All 
VIFs did not exceed a threshold of $5[43,44]$. Thus, there are no multicollinearity problems in this study. The indicator reliability of the measurement model was acceptable because the outer model loadings for all constructs were greater than 0.7 [45,46]. Every Cronbach's alpha of the five constructs exceeded the 0.7 threshold for internal consistency [47]. CR (Composite Reliability) for all constructs also exceeded the cutoff value of 0.7 and the AVE values exceeded the threshold value of $0.5[29,44]$. Thus, the reliability and convergent validity of the measurement model were satisfactory [48].

Table 5. Internal consistency and convergent validity.

\begin{tabular}{|c|c|c|c|c|c|c|}
\hline Variable & Item & $\begin{array}{l}\text { Indicator } \\
\text { Loading }\end{array}$ & VIF & $\begin{array}{c}\text { Cronbach's } \\
\text { Alpha }\end{array}$ & $\begin{array}{l}\text { Composite } \\
\text { Reliability }\end{array}$ & AVE \\
\hline \multirow{6}{*}{ Transparency } & TRANS1 & 0.817 & 2.075 & \multirow{6}{*}{0.882} & \multirow{6}{*}{0.910} & \multirow{6}{*}{0.628} \\
\hline & TRANS2 & 0.807 & 1.981 & & & \\
\hline & TRANS3 & 0.788 & 1.842 & & & \\
\hline & TRANS4 & 0.776 & 1.891 & & & \\
\hline & TRANS5 & 0.770 & 1.865 & & & \\
\hline & TRANS6 & 0.796 & 2.005 & & & \\
\hline \multirow{5}{*}{ Traceability } & TRACE1 & 0.849 & 2.342 & \multirow{5}{*}{0.880} & \multirow{5}{*}{0.912} & \multirow{5}{*}{0.675} \\
\hline & TRACE2 & 0.814 & 2.061 & & & \\
\hline & TRACE3 & 0.804 & 1.950 & & & \\
\hline & TRACE4 & 0.824 & 2.040 & & & \\
\hline & TRACE5 & 0.816 & 1.962 & & & \\
\hline \multirow{5}{*}{ Security } & SECUR1 & 0.851 & 2.184 & \multirow{5}{*}{0.892} & \multirow{5}{*}{0.920} & \multirow{5}{*}{0.698} \\
\hline & SECUR2 & 0.834 & 2.268 & & & \\
\hline & SECUR3 & 0.834 & 2.156 & & & \\
\hline & SECUR4 & 0.819 & 2.097 & & & \\
\hline & SECUR5 & 0.838 & 2.229 & & & \\
\hline \multirow{7}{*}{ Trust } & TRUST1 & 0.854 & 2.844 & \multirow{7}{*}{0.939} & \multirow{7}{*}{0.951} & \multirow{7}{*}{0.734} \\
\hline & TRUST2 & 0.852 & 2.814 & & & \\
\hline & TRUST3 & 0.860 & 2.864 & & & \\
\hline & TRUST4 & 0.840 & 2.559 & & & \\
\hline & TRUST5 & 0.894 & 3.639 & & & \\
\hline & TRUST6 & 0.853 & 2.788 & & & \\
\hline & TRUST7 & 0.841 & 2.594 & & & \\
\hline \multirow{5}{*}{ Satisfaction } & SATIS1 & 0.829 & 2.092 & \multirow{5}{*}{0.888} & \multirow{5}{*}{0.918} & \multirow{5}{*}{0.691} \\
\hline & SATIS2 & 0.867 & 2.509 & & & \\
\hline & SATIS3 & 0.797 & 1.922 & & & \\
\hline & SATIS4 & 0.842 & 2.230 & & & \\
\hline & SATIS5 & 0.821 & 2.070 & & & \\
\hline
\end{tabular}

Table 5 shows inter-construct correlations and the square root of the AVE for each construct. Values in the diagonal cells indicate the square root of the AVE. The square root of the AVE for each reflective construct is higher than its correlations with other constructs. According to the Fornell and Larcker criterion, the discriminant validity is satisfactory [48].

SamrtPLS provides two kinds of statistics for the criteria of discriminant validity. Table 6 shows inter-construct correlations and the square root of the AVE for each construct. Values in the diagonal cells indicate the square root of the AVE. The square root of the 
AVE for each construct is higher than its correlations with other constructs. According to the Fornell and Larcker criterion, the discriminant validity is satisfactory [48]. The HTMT (Heterotrait-Monotrait Ratio) was suggested as a criterion of discriminant validity by [46]. Discriminant validity is satisfactory for a given pair of constructs if the HTMT value is below 0.90 [43]. All values in Table 7 are less than 0.73 . Thus, discriminant validity was satisfied.

Table 6. Discriminant validity: Fornell-Larcker criterion.

\begin{tabular}{cccccc}
\hline Construct & TRANS & TRACE & SECUR & TRUST & SATIS \\
\hline TRANS & $\mathbf{0 . 7 9 2}$ & & & & \\
\hline TRACE & 0.268 & $\mathbf{0 . 8 2 2}$ & & & \\
\hline SECUR & 0.380 & 0.640 & $\mathbf{0 . 8 3 5}$ & & \\
\hline TRUST & 0.380 & 0.619 & 0.606 & $\mathbf{0 . 8 5 7}$ & $\mathbf{0 . 8 3 1}$ \\
\hline SATIS & 0.332 & 0.343 & 0.328 & 0.464 & \\
\hline
\end{tabular}

The square roots of AVE for the constructs are the bold values in the diagonal cells.

Table 7. Discriminant validity: HTMT.

\begin{tabular}{ccccc}
\hline Construct & TRANS & TRACE & SECUR & TRUST \\
\hline TRACE & 0.304 & & & \\
\hline SECUR & 0.423 & 0.722 & & \\
\hline TRUST & 0.416 & 0.681 & 0.658 & 0.506 \\
\hline SATIS & 0.373 & 0.387 & 0.362 & \\
\hline
\end{tabular}

Partial least squares structural equation modeling (PLS-SEM) was applied to test the research hypotheses of this study. The standardized root mean square residual (SRMR) is used for the goodness-of-fit of the structural equation model using PLS [43]. The goodnessof-fit refers to the extent to which the structural equation model fits the sample data. The goodness-of-fit is regarded to be high when the SRMR is not greater than the reference value of 0.08 [48]. The SRMR of this research model was found to be 0.042 , which is less than the threshold. GoF (Goodness of Fit) is also used to validate the PLS model globally [49]. A GoF value of 0.500 in the research model exceeds the cut-off value of 0.36 [23]. Thus, the structural equation model provided a satisfactory fit. The R-squared values of trust and satisfaction were shown not to be unsatisfactory at 0.481 and 0.248 , respectively [43].

Path coefficients are used to test research hypotheses using SmartPLS. Table 8 shows the results of the research hypotheses testing. The hypothesis that transparency positively affects distributed trust (H1) was supported at a significance level of 0.001 . The hypothesis that transparency positively affects satisfaction (H2) was supported at a significance level of 0.01. The hypothesis that traceability positively affects distributed trust (H3) was supported. However, the hypothesis that traceability positively affects satisfaction (H4) was not supported. The hypothesis that security positively affects distributed trust (H5) was supported. However, the hypothesis that security positively affects satisfaction (H6) was not supported. The hypothesis that distributed trust positively affects satisfaction (H7) was supported at a significance level of 0.001 . 
Table 8. Path coefficients and results of hypothesis testing.

\begin{tabular}{|c|c|c|c|c|c|c|}
\hline Hypothesis & Path & Path Coefficient & SD & T Statistics & $p$ & Result \\
\hline $\mathrm{H} 1$ & TRANS $\rightarrow$ TRUST & 0.164 & 0.052 & 3.129 & $0.001(* *)$ & Supported \\
\hline $\mathrm{H} 2$ & TRANS $\rightarrow$ SATIS & 0.179 & 0.055 & 3.252 & $\left.0.001{ }^{* *}\right)$ & Supported \\
\hline H3 & TRACE $\rightarrow$ TRUST & 0.385 & 0.072 & 5.356 & $0.000(* * *)$ & Supported \\
\hline $\mathrm{H} 4$ & TRACE $\rightarrow$ SATIS & 0.082 & 0.073 & 1.131 & 0.129 & Unsupported \\
\hline H5 & SECUR $\rightarrow$ TRUST & 0.298 & 0.070 & 4.241 & $0.000(* * *)$ & Supported \\
\hline H6 & SECUR $\rightarrow$ SATIS & -0.003 & 0.078 & 0.033 & 0.487 & Unsupported \\
\hline $\mathrm{H} 7$ & TRUST $\rightarrow$ SATIS & 0.347 & 0.074 & 4.682 & $0.000(* * *)$ & Supported \\
\hline
\end{tabular}

SmartPLS provides the direct, indirect, and total effects of the structural equation model. Table 9 shows the indirect effects of distributed trust between exogenous latent variables (transparency, traceability, and security) and satisfaction. The indirect effects of distributed trust were significant in all three paths. Transparency, traceability, and security have a significant impact on satisfaction through distributed trust as a mediation.

Table 9. Indirect and total effects.

\begin{tabular}{ccccc}
\hline \multirow{2}{*}{ Mediation Path } & \multicolumn{2}{c}{ Indirect Effect } & \multicolumn{2}{c}{ Total Effect } \\
\cline { 2 - 5 } & Effect & $\boldsymbol{p}$-Value & Effect & $p$-Value \\
\hline $\mathrm{TRANS} \rightarrow$ TRUST $\rightarrow$ SATIS & 0.057 & 0.007 & 0.236 & 0.000 \\
\hline $\mathrm{TRACE} \rightarrow$ TRUST $\rightarrow$ SATIS & 0.133 & 0.000 & 0.216 & 0.002 \\
\hline $\mathrm{SECUR} \rightarrow$ TRUST $\rightarrow$ SATIS & 0.103 & 0.001 & 0.101 & 0.102 \\
\hline
\end{tabular}

The PROCESS macro (Model 4) [50] is frequently used to verify mediating effects. As shown in Table 10, a 95\% bias-corrected bootstrap CIs (confidence intervals) for the transparency independent variable is above zero in both direct and indirect effect. A 95\% bias-corrected bootstrap CIs for traceability and security independent variables are above zero in indirect effects. Thus, distributed trust plays a mediating role between the three independent variables (transparency, traceability, and security) and user satisfaction.

Table 10. Mediating effect of distributed trust on satisfaction.

\begin{tabular}{cccc}
\hline Variable & \multicolumn{2}{c}{ Effect } & 95\% Bias-Corrected Bootstrap CI \\
\hline \multirow{2}{*}{ Transparency } & Direct effect & 0.1759 & 0.0757 to 0.2782 \\
\cline { 2 - 4 } & Indirect effect & 0.1159 & 0.0601 to 0.1766 \\
\hline \multirow{2}{*}{ Traceability } & Direct effect & 0.0693 & -0.0242 to 0.1628 \\
\cline { 2 - 4 } & Indirect effect & 0.2579 & 0.1788 to 0.3413 \\
\hline \multirow{2}{*}{ Security } & Direct effect & 0.0554 & -0.0439 to 0.1548 \\
\cline { 2 - 4 } & Indirect effect & 0.2653 & 0.1791 to 0.3505 \\
\hline
\end{tabular}

\section{Conclusions}

Blockchain is an enabler of distributed transaction and management instead of a centralized approach with third parties. A variety of stakeholders as actors of business ecosystems participate in the blockchain-based food supply chain. Participants including producers, processors, distributors, retailers, consumers, and regulators want to have transparent, traceable, and secure transactions. Our findings suggest that transparency, traceability, and security are determinants of distributed trust in the food supply chain. Transparency has a significant influence on user satisfaction. In particular, distributed trust 
plays a mediating role in relationships between the three determinants and satisfaction. Two characteristics of blockchain technology, traceability and security, indirectly affect user satisfaction, although these two variables do not directly influence it.

Blockchain technology has been mainly applied and diffusing in the areas of the cryptocurrency and finance industry initiated by Bitcoin since 2009. Hyperledger began in December 2015 by the Linux Foundation. Since 2008, companies such as IBM, Walmart, Alibaba, and JD.com have launched solution services for food supply chain management until 2018. Applications of blockchain to the supply chain are still in the initial stages. Most of all studies have focused on technical approaches regarding blockchain applications. The present study can be a guide for future behavioral studies for blockchain applications.

The present study contributes to the advancement of research regarding trust-free systems and the relationship between system-like trust and human-like trust in technology. Trust in technology exists along a continuum of technology's humanness, which is represented by the extent to which users perceive it to be more human-like or systems-like [50]. Human-like trust consists of integrity, ability, and benevolence, whereas system-like trust includes reliability, functionality, and helpfulness. According to the authors of [51,52], more human-like technology such as Facebook and Airbnb is strongly associated with usefulness and continuance intention, whereas more system-like technologies like MS Access and Expedia.com had a stronger influence on usefulness and continuance intention. The blockchain-based supply chain resembles the system-like technology more than the human-like technology. Our findings imply that three determinants of distributed trust, including transparency, traceability, and security, improve trust in technology.

Three papers deal with trust in blockchain and trust-free issues [11,53,54]. Ref. [54] suggested multi-dimensions of factors influencing trust in blockchain by using data collected from interviews and applying grounded theory. Factors including security, technology development, disintermediation, privacy, convenience, personal innovativeness, and economic factors [53] were used to examine issues regarding trust-free systems based on blockchain by applying a systematic literature review. Both studies focused on Bitcoin and payment systems as application domains of blockchain. The authors of [11] designed a system based on smart contracts of Ethereum, where smart contracts play the role of escrow, mediating the interactions between forecasters and requesters under online crowdsourcing settings. The authors of [55] discussed the limits of trust-free systems based on blockchain technology in the sharing economy.

Blockchain-based systems can be an alternative for solving distrust problems resulting from human opportunistic behaviors, arbitrary judgments, and mistakes without a trusted third party. Trust-free systems can be designed and implemented by applying blockchain and smart contracts to a specific scope and within a given governance like a vending machine in a physical world. In general, blockchain technology including smart contracts contributes to trustworthy systems enabling more transparent, traceable, and secure transactions, and also accelerates decentralized organizational structure and business ecosystems. Although blockchain can partially shift trust in people and institutions to trust in technology in a specific domain, human roles as well as law and institutions, are still crucial to build trust in the blockchain-based supply chain for sustainable businesses. Issues regarding the relationship between the trust-free system and sustainability remain for further research. In addition, further research dealing with the relationship between distributed trust and smart contracts also needs to be followed. Our research model can be applied to many areas related to trust based on blockchain. An empirical study regarding the relation of blockchain technology and sustainability is an important further research area. OECD argues that blockchain is an enabler for sustainable services through a case study in the areas of emissions certificate trading systems and contract management systems because transparency, security, and process efficiency can be leveraged to drive the systematic changes by providing sustainable infrastructure [56]. 
Author Contributions: Conceptualization, J.J.; methodology, J.J.; software, J.J.; validation, J.J.; formal analysis, J.J.; investigation, J.J. and Y.H.; resources, J.J. and Y.H.; data curation, Y.H. and J.J.; writingoriginal draft preparation, J.J.; writing — review and editing, J.J.; visualization, J.J.; supervision, J.J.; project administration, J.J.; funding acquisition, J.J. All authors have read and agreed to the published version of the manuscript.

Funding: The Republic of Korea and the National Research Foundation of Korea (NRF-2020S1A5A2A 01041201).

Institutional Review Board Statement: Not applicable.

Informed Consent Statement: Not applicable.

Acknowledgments: “This work was supported by the Dongguk University Research Fund of 2021" and "This work was supported by the Ministry of Education of the Republic of Korea and the National Research Foundation of Korea (NRF-2020S1A5A2A01041201)".

Conflicts of Interest: The authors declare no conflict of interest.

\section{References}

1. Khanfar, A.A.A.; Iranmanesh, M.; Ghobakhloo, M.; Senali, M.G.; Fathi, M. Applications of blockchain technology in sustainable manufacturing and supply chain management: A systematic review. Sustainability 2021, 13, 7870. [CrossRef]

2. Gaur, V.; Gaiha, A. Building a Transparent Supply Chain: Blockchain Can Enhance Trust, Efficiency, and Speed. Harvard Business Review, 2020. Available online: https:/ / hbr.org/2020/05/building-a-transparent-supply-chain (accessed on 15 May 2021).

3. Tian, F. An Information System for Food Safety Monitoring in Supply Chains Based on HACCP, Blockchain and Internet of Things. Ph.D. Thesis, WU Vienna University of Economics and Business, Vienna, Austria, 2018.

4. Varriale, V.; Cammarano, A.; Michelino, F.; Caputo, M. Sustainable supply chains with blockchain, IoT and RFID: A simulation on order management. Sustainability 2021, 13, 6372. [CrossRef]

5. Hyperledger Fabric. Available online: https://www.hyperledger.org/use/fabric (accessed on 22 August 2021).

6. Wang, Y.; Chen, K.; Hao, M.; Yang, B. Food safety traceability method based on blockchain technology. J. Phys. Conf. Ser. 2020, 1634, 012025. [CrossRef]

7. Toptanc1, A.İ. Using IBM Food Trust Blockchain in the Food Supply Chain: A Research on Walmart; ZBW-Leibniz Information Centre for Economics: Kiel, Hamburg, 2021. Available online: https:/ /www.econstor.eu/handle/10419/228470 (accessed on 12 April 2021).

8. Abdul-Rahman, A.; Hailes, S. A distributed trust model. In Proceedings of the 1997 Workshop on New Security Paradigms, NSPW '97, Langdale, UK, 23-26 September 1997; pp. 48-60. [CrossRef]

9. Jiang, J.; Han, G.; Wang, F.; Shu, L.; Guizani, M. An efficient distributed trust model for wireless sensor networks. IEEE Trans. Parallel Distrib. Syst. 2015, 26, 1228-1237. [CrossRef]

10. Botsman, R. Who Can You Trust? How Technology Brought Us Together and Why It Might Drive Us Apart; Penguin: London, UK, 2017.

11. Carvalho, A.; Karimi, M. How blockchain can bring trust and transparency to the payment of crowd forecasters. In Proceedings of the ICIS 2020-Making Digital Inclusive: Blending the Local and the Global, online, 13-16 December 2020.

12. Werbach, K. The Blockchain and the New Architecture of Trust; MIT Press: Cambridge, MA, USA, 2018.

13. Joo, J.; Park, J.; Han, Y. Applications of blockchain and smart contract for sustainable tourism ecosystems. In Evolutionary Computing and Mobile Sustainable Networks; Suma, V., Bouhmala, N., Wang, H., Eds.; Lecture Notes on Data Engineering and Communications Technologies 53; Springer: Singapore, 2021.

14. Bamakan, S.M.H.; Motavali, A.; Bondarti, A.B. A survey of blockchain consensus algorithms performance evaluation criteria. Expert Syst. Appl. 2020, 154, 113385. [CrossRef]

15. Pant, R.R.; Prakashb, G.; Farooquiea, J.A. A framework for traceability and transparency in the dairy supply chain networks. Procedia Soc. Behav. Sci. 2015, 189, 385-394. [CrossRef]

16. Grecuccio, J.; Giusto, E.; Fiori, F.; Rebaudengo, M. Combining blockchain and IoT: Food-chain traceability and beyond. Energies 2020, 13, 3820. [CrossRef]

17. Androulaki, E.; Barger, A.; Bortnikov, V.; Cachin, C.; Christidis, K.; De Caro, A.; Enyeart, D.; Ferris, C.; Laventman, G.; Manevich, Y.; et al. Hyperledger Fabric: A distributed operating system for permissioned blockchains. In Proceedings of the EuroSys '18: Thirteenth EuroSys Conference, Porto, Portugal, 23-26 April 2018; pp. 1-15.

18. Bellini, E.; Iraqi, Y.; Damiani, E. Blockchain-based distributed trust and reputation management systems: A survey. IEEE Access 2020, 8, 21127-21151. [CrossRef]

19. Song, J.; Zhang, P.; Alkubati, M.; Bao, Y.; Yu, G. Research advances on Blockchain-as-a-Service: Architectures, applications and challenges. Digit. Commun. Netw. 2021. [CrossRef]

20. Abeyratne, S.A.; Monfared, R.P. Blockchain ready manufacturing supply chain using distributed ledger. Int. J. Res. Eng. Technol. 2016, 5, 1-10. 
21. Edelman. Edelman Trust Barometer. 2018. Available online: https://www.edelman.com/sites/g/files/aatuss191/files/2018-10/ 2018_Edelman_Trust_Barometer_Global_Report_FEB.pdf (accessed on 12 May 2020).

22. Giannini, L.; Terenzi, M. Trust, transparency and disintermediation: An analysis of blockchain implementation in the supply-chain. Med. J. 2020, 16, 97-114.

23. Li, F.; Lu, H.; Hou, M.; Cui, K.; Darbandi, M. Customer satisfaction with bank services: The role of cloud services, security, e-learning and service quality. Technol. Soc. 2021, 64, 101487. [CrossRef]

24. ISO 9000. Quality Management Systems-Fundamentals and Vocabulary. 2005. Available online: https://www.iso.org/obp/ui/ \#iso:std:iso:9000:ed-3:v1:en (accessed on 12 April 2020).

25. Wamba, S.F.; Queiroz, M.M.; Trinchera, L. Dynamics between blockchain adoption determinants and supply chain performance: An empirical investigation. Int. J. Prod. Eco. 2020, 229, 107791. [CrossRef]

26. Venkatesh, V.; Thong, J.Y.L.; Chan, F.K.Y.; Hu, P.J.H. Managing citizens' uncertainty in e-Government services: The mediating and moderating roles of transparency and trust. Inf. Syst. Res. 2016, 27, 87-111. [CrossRef]

27. Aung, M.M.; Chang, Y.S. Traceability in a food supply chain: Safety and quality perspectives. Food Control 2014, 39, 172-184 [CrossRef]

28. Miraz, M.; Hasan, M.; Sumi, F.; Sarkar, S.; Majumder, M.I. The Innovation of blockchain transparency \& traceability in logistic food chain. Int. J. Mech. Prod. Eng. Res. Dev. 2020, 10, 9155-9170.

29. Fornell, C.; Johnson, M.D.; Anderson, E.W.; Cha, J.; Bryant, B.E. The American customer satisfaction index: Nature, purpose, and findings. J. Mark. 1996, 60, 7-18. [CrossRef]

30. Hsu, S.H. Developing an Index for Online Customer Satisfaction: Adaptation of American Customer Satisfaction Index. Expert Syst. Appl. 2008, 34, 3033-3042. [CrossRef]

31. Bateman, A.; Bonanni, L. What supply chain transparency really means. Harvard Business Review, 2019. Available online: https:/ /hbr.org/2019/08/what-supply-chain-transparency-really-means (accessed on 12 April 2020).

32. Queiroza, M.M.; Wambab, S.F. Blockchain adoption challenges in supply chain: An empirical investigation of the main drivers in India and the USA. Int. J. Inf. Manag. 2019, 46, 70-82. [CrossRef]

33. OECD. OECD Due Diligence Guidance for Responsible Supply Chains in the Garment and Footwear Sector. 2017. Available online: https:/ / mneguidelines.oecd.org/oecd-due-diligence-guidance-garment-footwear.pdf (accessed on 12 April 2019).

34. Manzini, R.; Accorsi, R. The new conceptual framework for food supply chain assessment. J. Food Eng. 2013, 115, 251-263. [CrossRef]

35. Grabner-Krautera, S.; Kaluscha, E.A. Empirical research in on-line trust: A review and critical assessment. Int. J. Hum.-Comp. Stud. 2003, 58, 783-812. [CrossRef]

36. Kowalski, M.; Lee, Z.W.Y.; Chan, T.K.H. Blockchain technology and trust relationships in trade finance. Technol. Forecast. Soc. Change 2021, 166, 120641. [CrossRef]

37. Islam, T.; Islam, R.; Pitafi, A.H.; Xiaobei, L.; Rehmani, M.; Irfan, M.; Mubarak, M.S. The impact of corporate social responsibility on customer loyalty: The mediating role of corporate reputation, customer satisfaction, and trust. Sustain. Prod. Consum. 2021, 25, 123-135. [CrossRef]

38. Liang, L.J.; Choi, H.C.; Joppe, M. Exploring the relationship between satisfaction, trust and switching intention, repurchase intention in the context of Airbnb. Int. J. Hosp. Manag. 2018, 69, 41-48. [CrossRef]

39. Li, B.; Wu, Y.; Hao, Z.; Yan, X.; Chen, B. The effects of trust on life satisfaction in the context of WeChat use. Telemat. Inform. 2019, 42, 101241. [CrossRef]

40. Li, X.; Jiang, P.; Chen, T.; Luo, X.; Wen, Q. A survey on the security of blockchain systems. Future Gener. Comput. Syst. 2020, 107, 841-853. [CrossRef]

41. Albayatia, H.; Kim, S.K.; Rho, J.J. Accepting financial transactions using blockchain technology and cryptocurrency: A customer perspective approach. Technol. Soc. 2020, 62, 101-320.

42. Ringle, C.M.; Wende, S.; Becker, J.M. SmartPLS 3; SmartPLS GmbH: Boenningstedt, Germany, 2015. Available online: http: / /www.smartpls.com (accessed on 12 April 2020).

43. Garson, G.D. Partial Least Squares: Regression \& Structural Equation Models. 2016. Available online: https://www.smartpls. com/resources/ebook_on_pls-sem.pdf (accessed on 12 April 2020).

44. Kock, N.; Lynn, G.S. Lateral collinearity and misleading results in variance-based SEM: An illustration and recommendations. J. Assoc. Inf. Syst. 2012, 13, 546-580. [CrossRef]

45. Hair, J.F., Jr.; Hult, G.T.M.; Ringle, C.M.; Sarstedt, M. A Primer on Partial Least Squares Structural Equation Modeling (PLS-SEM); Sage Publications: Thousand Oaks, CA, USA, 2014.

46. Henseler, J.R.; Ringle, C.M.; Sarstedt, M.A. New criterion for assessing discriminant validity in variance-based structural equation modeling. J. Acad. Mark. Sci. 2015, 43, 115-135. [CrossRef]

47. Nunnally, J.C.; Bernstein, I.H. Psychometric Theory, 3rd ed.; McGraw-Hill: New York, NY, USA, 1994.

48. Fornell, C.; Larcker, D.F. Evaluating structural equation models with unobservable variables and measurement error. J. Mark. Res. 1981, 18, 39-50. [CrossRef]

49. Wetzels, M.; Odekerken-Schroder, G.; Van Oppen, C. Using PLS path modeling for assessing hierarchical construct models: Guidelines and empirical illustration. MIS Q. 2009, 33, 177-195. [CrossRef] 
50. Hayes, A.F. Introduction to Mediation, Moderation, and Conditional Process Analysis: A Regression-Based Approach; Guilford Press: New York, NY, USA, 2013.

51. Lankton, N.K.; McKnight, D.H.; Tripp, J. Technology, humanness, and trust: Rethinking trust in technology. J. Assoc. Inf. Syst. 2015, 16, 880-918. [CrossRef]

52. Califfa, C.B.; Brooksb, S.; Longstreet, P. Human-like and system-like trust in the sharing economy: The role of context and humanness. Technol. Forecast. Soc. Change 2020, 154, 119968. [CrossRef]

53. Auinger, A.; Riedl, R. Blockchain and trust: Refuting some widely-held misconceptions. In Proceedings of the International Conference on Information Systems, San Francisco, CA, USA, 13-16 December 2018.

54. Ostern, N. Do you trust a trust-free transaction? Toward a trust framework model for blockchain technology. In Proceedings of the International Conference on Information Systems, San Francisco, CA, USA, 13-16 December 2018.

55. Hawlitschek, F.; Notheisen, B.; Teubner, T. The limits of trust-free systems: A literature review on blockchain technology and trust in the sharing economy. Electron. Commer. Res. Appl. 2018, 29, 50-63. [CrossRef]

56. OECD. Financing Climate Futures: Blockchain Technologies as a Digital Enabler for Sustainable Infrastructure. In Financing Climate Futures: Rethinking Infrastructure Initiative; OECD: Geneva, Switzerland, 2019. Available online: https://www.oecd.org/finance/ Blockchain-technologies-as-a-digital-enabler-for-sustainable-infrastructure-key-findings.pdf (accessed on 9 September 2021). 